\title{
Investigating Teacher Learning Supports in High School Biology Curricular Programs to Inform the Design of Educative Curriculum Materials
}

\author{
Carrie J. Beyer, Cesar Delgado, Elizabeth A. Davis, Joseph Krajcik \\ School of Education, University of Michigan, Ann Arbor, Michigan 48109
}

Received 29 August 2007; Accepted 5 January 2009

\begin{abstract}
Reform efforts have emphasized the need to support teachers' learning about reform-oriented practices. Educative curriculum materials are one potential vehicle for promoting teacher learning about these practices. Educative curriculum materials include supports that are intended to promote both student and teacher learning. However, little is known about the extent to which existing curriculum materials provide support for teachers and the ways they can be improved. In this study, eight sets of high school biology curriculum materials were reviewed to determine their potential for promoting teacher learning. Design heuristics for educative curriculum materials were adapted for use as evaluation criteria. From this analysis, several themes emerged. First, the materials tended to provide support for teachers' subject matter knowledge and pedagogical content knowledge for students' ideas (e.g., misconceptions) but rarely for their pedagogical content knowledge of scientific inquiry. Second, the materials contained several implementation guidance supports but far fewer rationales for instructional decisions, which are an important feature of educative curriculum materials. Finally, the quality of support varied widely, differing in its degree of relevance, pedagogical helpfulness, and depth. The article concludes with recommendations for the redesign of existing curriculum materials. (C) 2009 Wiley Periodicals, Inc. J Res Sci Teach 46: 977-998, 2009

biology; textbooks; teacher education-practicing teachers; teacher cognition; secondary
\end{abstract}

Curriculum materials play a fundamental role in the design of instruction for students. These materials typically contain content and skills for students to learn, provide activities for teaching these ideas, and specify particular pedagogical methods (Remillard, 2000). Curriculum materials include a variety of different types of resources for students (e.g., textbooks, worksheets, science journals) and teachers (e.g., teacher editions of student textbooks, teacher guides, science kits). Teachers often use curriculum materials to guide their planning and enactment of lessons (Ball \& Cohen, 1996). Teachers teaching outside their content area and teachers entering the field tend to rely extensively on such materials (Ball \& Feiman-Nemser, 1988; Grossman \& Thompson, 2004). "Of all the different instruments for conveying educational policies [curriculum materials] exert perhaps the most direct influence on the tasks that teachers actually do with their students each day in the classroom" (Brown \& Edelson, 2003, p. 1).

Using curriculum materials to convey educational policy in science education is not a new idea. In the 1950s and 1960s, content experts developed novel curriculum materials in an attempt to improve science instruction (Lazarowitz, 2007; Welch, 1979). While these materials were widely adopted, the curriculum reform efforts were largely ineffective. These materials failed to effect change, in part, because curriculum developers neglected to consider the role teachers play in enacting the materials (Stake \& Easley, 1978; Welch, 1979). Even though these materials were designed to support student learning, they failed to help teachers use the materials in productive ways that would not misrepresent the core vision of the reform (Krajcik, Mamlok, \& Hug, 2001).

\footnotetext{
Contract grant sponsor: National Science Foundation; Contract grant number: ESI-0455846.

Correspondence to: C.J. Beyer; E-mail: cjbeyer@umich.edu

DOI 10.1002/tea.20293

Published online 29 July 2009 in Wiley InterScience (www.interscience.wiley.com).
} 
Current reform efforts call for educators to develop students' understandings and abilities with regard to scientific inquiry (American Association for the Advancement of Science [AAAS], 1993; National Research Council [NRC], 1996, 2000). Teaching science as inquiry entails engaging students in asking scientific questions, conducting investigations to answer those questions, and building evidence-based explanations (Krajcik, Blumenfeld, Marx, \& Soloway, 2000). To support teachers in enacting reform-oriented practices, researchers have begun to explore how curriculum materials might help teachers learn about these practices (Schneider \& Krajcik, 2002). Such materials have been termed educative curriculum materials (Collopy, 2003; Davis \& Krajcik, 2005). Research has shown that teachers who use educative curriculum materials can develop their knowledge of content and learners and expand their repertoire of instructional practices (Schneider, 2006; Schneider \& Krajcik, 2002).

Despite the potential of educative curriculum materials, little is known about the extent to which existing science curriculum materials might support teacher learning. Project 2061 (AAAS, 2005; Kesidou \& Roseman, 2002; Stern \& Roseman, 2004) and others (Abd-El-Khalick, Waters, \& Le, 2008; Hubisz, 2003; Sullivan, 2008) have conducted reviews of science curriculum materials, but their reviews have primarily focused on how well these materials promote students' learning of science and the nature of science, not teachers' learning of how to teach science. This study addresses this gap by examining the quantity and quality of teacher learning supports within currently available biology high school curriculum materials.

\section{Theoretical Framework}

Developing expertise in science teaching entails forming an integrated understanding of multiple knowledge types that are crucial for promoting students' learning of science. Curriculum materials with embedded supports may play an important role in helping teachers develop this knowledge.

\section{Dimensions of Teacher Learning}

Teaching is a complex practice. In order to deal with this complexity, teachers need to develop their knowledge in a variety of domains. Like students, teachers need to develop a robust understanding of the subject matter content to be taught (Shulman, 1986). However, unlike students, teachers must also develop knowledge related to the teaching of subject matter, that is, pedagogical content knowledge (PCK). PCK entails having knowledge of learners, including understanding the difficulties students face in learning the subject matter and how to deal with those difficulties (Borko \& Putnam, 1996; Grossman, 1990; Shulman, 1986). It also includes knowledge of strategies for identifying, interpreting, and working with students' likely ideas about a subject. Knowledge of instructional strategies for representing the subject matter is another component of PCK (Grossman, 1990; Shulman, 1986). Such knowledge not only includes a repertoire of classroom approaches and strategies but also an understanding of how to effectively use such instructional strategies for specific topics. Additionally, it includes standards for assessing the appropriateness of different representations (McDiarmid, Ball, \& Anderson, 1989) and an understanding of why particular representations are pedagogically appropriate for promoting student learning.

With regard to helping students develop their understanding of science specifically, teachers need to develop PCK for science topics. They need to have knowledge of their students' ideas about science, sciencespecific instructional strategies and representations, science curriculum materials, and strategies for assessing scientific literacy as well as an orientation toward science teaching that demonstrates an understanding of the purposes for teaching science (Abell, 2007; Magnusson, Krajcik, \& Borko, 1999). Teachers must also possess PCK for scientific inquiry practices, in order to help students develop their understandings about and abilities necessary to engage in scientific inquiry (Davis \& Krajcik, 2005; Petish, 2004; Zembal-Saul \& Dana, 2000). This entails learning how to engage students in asking and answering scientific questions, designing and conducting investigations, collecting and analyzing data, developing explanations based on evidence, and communicating and justifying findings (NRC, 2000). Developing expertise in all of these knowledge domains is essential for negotiating the high demands of teaching and promoting students' learning of reform-oriented science (AAAS, 1993; NRC, 1996, 2000). 


\section{Role of Curriculum Materials in Fostering Teacher Learning}

Curriculum materials may play a key role in promoting teacher learning (Ball \& Cohen, 1996; Collopy, 2003; Davis \& Krajcik, 2005; Remillard, 2000; Schneider \& Krajcik, 2002). As noted above, materials intended to be educative for teachers, in addition for students, are called educative curriculum materials. Educative curriculum materials are intentionally designed to promote teachers' learning about content and pedagogy as they use the materials to foster students' learning about the subject matter. Even though several forms of professional development can promote teacher learning, embedding supports for teachers within curriculum materials is a fruitful option for many reasons. Curriculum materials are connected to teachers' daily work and thus can situate their learning in their own practice (Putnam \& Borko, 2000) and provide ongoing support (Collopy, 2003). They can also foster teacher learning on a large scale, unlike other reform efforts aimed at state and district levels (Schneider \& Krajcik, 2002). Thus, curriculum materials may be effective tools in promoting change in how science is taught.

Curriculum materials designed with just students in mind tend to only provide teachers with directions to follow, problems to assign, and questions to discuss (Remillard, 2000). They provide teachers with activities and tasks and then assume that they will simply "deliver" them to their students. By only providing teachers with activities to use, curriculum developers assume teachers will examine the new ideas for themselves, act upon them, and eventually integrate them into their own practice. "This approach to guiding teaching emphasizes the outcomes of teaching and not the rationales, assumptions, or agendas supporting them, discouraging teachers from engaging the ideas underlying the writers' decisions and suggestions" (Remillard, 2000, p. 347). Because teaching science as inquiry entails ambitious learning goals for students and thus is complex and difficult for teachers to enact (Marx, Blumenfeld, Krajcik, \& Soloway, 1997; Roehrig \& Luft, 2004), this level of support is insufficient for most teachers enacting reform-oriented instruction. Many teachers also have not experienced inquiry-based instruction as learners and thus need guidance in enacting this type of instruction (Windschitl, 2002).

In contrast, educative curriculum materials do more than simply prescribe what and how to teach. They are "designed to speak to teachers, not merely through them" (Remillard, 2000, p. 347). One way educative curriculum materials speak to teachers is by providing rationales for ideas and suggestions given in the materials (Ball \& Cohen, 1996; Beyer \& Davis, in press; Davis \& Krajcik, 2005; Petish, 2004; Remillard, 2000; Schneider, 2006). For example, in order to help teachers engage students in building evidence-based explanations, curriculum materials might help teachers understand why engaging students in this scientific practice is important by explaining that it can help students develop their understanding of science content as well as their understandings about the work of scientists. Rationales help teachers understand why particular instructional approaches and content are pedagogically and scientifically appropriate, thereby engaging them in the ideas underlying the pedagogical decisions made by curriculum developers. Helping teachers understand why specific science concepts and strategies for teaching those concepts are included in curriculum materials allows them to examine the assumptions beneath curricular suggestions, and in turn, make informed decisions about how to design instruction for their students and local context.

Educative materials can also foster teacher learning by providing teachers with implementation guidance-detailed recommendations for how to use curricular suggestions to achieve productive instructional ends (Beyer \& Davis, in press; Collopy, 2003; Petish, 2004; Remillard, 2000; Schneider, 2006; Schneider \& Krajcik, 2002). An example of implementation guidance might include helping teachers learn how to engage their students in explanation construction by suggesting that they have students identify the different components of a scientific explanation or critique strong and weak examples of explanations. Additionally, educative materials that are consistent with reform documents can help teachers learn about new ideas for teaching the subject matter, practice these ideas in their instruction, and reflect upon their experiences (Borko \& Putnam, 1996; Collopy, 2003; Grossman \& Thompson, 2004; McNeill \& Krajcik, 2008; Remillard, 2000; Schneider, Krajcik, \& Blumenfeld, 2005).

Recent research investigating the role of educative curriculum materials in promoting teacher learning suggests that such materials can support the development of teacher knowledge. For example, Schneider and Krajcik (2002) examined three middle school teachers' use of educative curriculum materials. The teachers reported reading educative supports intended to increase their subject matter knowledge and stated that they 
found them to be useful for understanding the physics content. The researchers also observed the teachers using the information in the supports with their students in class, though the teachers varied in their understanding of more complex ideas. Additional studies have found that educative curriculum materials can support teachers in developing several aspects of their PCK, such as their knowledge of learners and their repertoire of instructional practices for promoting student learning (Beyer \& Davis, in press; Collopy, 2003; McNeill \& Krajcik, 2008; Petish, 2004; Remillard, 2000; Schneider, 2006; Schneider \& Krajcik, 2002; Schneider et al., 2005). For example, Schneider and Krajcik (2002) found that teachers who read embedded notes intended to support their PCK were able to describe how science-specific strategies and representations could support student learning and to use them with students, though the teachers varied in how successful they were in enacting these strategies and representations in classroom practice.

While these studies suggest that curriculum materials designed with explicit pedagogical support can play a role in supporting teacher learning, they also highlight the idea that how teachers use curriculum materials and what they learn from them can vary among teachers (Cohen \& Ball, 1999; Remillard, 2005; Tarr, Chavez, Reys, \& Reys, 2006). This variation occurs because both teachers and curriculum materials actively participate in the design and enactment of lessons. As teachers read and interpret written materials, they draw upon their unique set of experiences, beliefs, knowledge, and goals. These personal resources help teachers bring meaning to materials, which, in turn, mediate what they learn from them and how they enact them in practice (Brown, 2009; Collopy, 2003; Remillard, 2000; Schneider \& Krajcik, 2002). Likewise, curriculum materials serve as active participants by specifying particular science topics to teach, pedagogical methods to use, and in the case of educative curriculum materials, guidance for implementation and adaptation as well as rationales for recommendations. These curricular features shape teachers' ideas about what and how to teach and ultimately how they use the materials in practice (Brown, 2009; Cohen \& Ball, 1999). Thus, both curricular resources and teachers' personal resources impact the enactment of written materials and the learning opportunities afforded to both students and teachers.

\section{Purpose of the Present Study}

In order to assess the extent to which existing curriculum materials support teachers, we evaluated eight sets of high school biology curriculum materials to determine their potential for promoting teacher learning, focusing primarily on teacher guides and teacher editions of textbooks. We derived the evaluation criteria from design heuristics for educative curriculum materials (Davis \& Krajcik, 2005). The research questions guiding our study include:

(1) What is the relative frequency of different types of educative supports across curriculum materials?

(a) What is the relative frequency of support for teachers' subject matter knowledge, PCK for science topics, and PCK for scientific inquiry?

(b) What is the relative frequency of rationales and implementation guidance supports?

(2) What is the quality of educative supports across curriculum materials?

By uncovering how and to what extent existing biology curriculum materials provide educative supports for teachers, we illuminate the strengths of existing curriculum materials as well as their limitations and gaps in promoting teacher learning, concluding with suggestions for the improvement of science curriculum materials.

\section{Methods}

This curriculum review focused on eight science programs written for introductory high school biology students. These eight programs were chosen for our review by the leadership of the larger project (Gess-Newsome, Powell, Taylor, \& Gardner, 2008; Powell \& Gess-Newsome, 2008), of which this study is a part, and were intended to represent a range of materials typically used to teach high school biology. In 2000, Biology: The Dynamics of Life (Biggs et al., 2005) and Biology (Miller \& Levine, 2006) were two of the three most commonly used high school biology textbooks, while BSCS Biology: A Human Approach (Biological 
Sciences Curriculum Study [BSCS], 2006a), BSCS Biology: An Ecological Approach (BSCS, 2006b), and Insights in Biology (Education Development Center [EDC], 1998) together accounted for less than $2 \%$ of the market share (Weiss, Banilower, McMahon, \& Smith, 2001, p. 83-84). In addition, the National Science Foundation funded four of the eight programs reviewed in this study (BSCS, 2006a,b; EDC, 1998; Leonard \& Penick, 2003). Most of the programs were recently developed, being in their first, second, or third edition, while one program (BSCS, 2006b) was in its tenth edition, with its first edition dating back to the 1960s. All programs were recent editions, with seven programs edited in 2003 or later. Also, six of the curricular programs evaluated in this study were included in Project 2061's recent evaluation of high school biology textbooks (AAAS, 2005), allowing for a more complete characterization of the individual programs and of high school biology materials in general.

The materials in this analysis varied greatly with regard to the format and location of their educative supports. The supports varied in how embedded they were, that is, the extent to which they were integrated within the specific directions and content found in the student text. The supports also differed in their degree of explicitness, that is, how easily they could be found in the materials and how clearly they specified the types of teacher knowledge supported. For example, some materials were formatted as teacher editions of student textbooks with wraparound text (Biggs et al., 2005; Biggs, Kaskel, Lundgren, \& Mathieu, 2003; BSCS, 2006b; Kaskel, Hummer, \& Daniel, 2003; Miller \& Levine, 2006). The wraparound text included the educative supports, which were close by but separate from the specific ideas/steps found in the student text. Thus, the supports were not embedded. Additionally, these materials typically made explicit the location of the teacher-learning supports and the types of support provided. For example, educative supports were found in designated sections containing specific headings denoting the type of support provided. Typical headings included Misconceptions, Teacher Background Information, Prior Knowledge, Things to Watch For, and Use Visuals. In contrast, some materials were formatted as teacher guides keyed to but separate from the student textbook (BSCS, 2006a; EDC, 1998; Leonard \& Penick, 2003). These materials included excerpts from or pointers to specific places in the student text, and next to the excerpts or pointers, had relevant supports for teachers. Thus, these supports were embedded. Additionally, the materials typically made explicit which sections were intended to support teacher learning but did not make explicit the types of knowledge targeted in each support. Most educative supports were found in specific sections containing general headings such as Instructional Notes and Teaching Strategy or were bolded in order to stand apart from the rest of the text. Table 1 summarizes the embeddedness and explicitness of educative supports across the eight curricular programs.

Our sampling procedure focused the review to two topics: (a) natural selection and evolution and (b) ecology and the environment. These are important topics in the national science education reform documents (AAAS, 1993; NRC, 1996) and are a focus in the larger project, of which this study is a part (Gess-Newsome et al., 2008). To allow comparisons in the frequency of supports across materials, 50 pages were evaluated for each topic within each program. Totals from programs with fewer than 50 pages on a topic were proportionally scaled up for purposes of comparison. Within each program, teacher materials

Table 1

Degree of embeddedness and explicitness of education supports across curricular programs

\begin{tabular}{|c|c|c|c|}
\hline Curricular Program & Format of Teacher Materials & $\begin{array}{l}\text { Embeddedness } \\
\text { of Supports }\end{array}$ & $\begin{array}{l}\text { Explicitness } \\
\text { of Supports }\end{array}$ \\
\hline Biology: An Ecological Approach (BSCS, 2006b) & Teacher edition of student text & Not embedded & Not explicit \\
\hline $\begin{array}{l}\text { Biology: An Everyday Experience (Kaskel et al., } \\
\text { 2003) }\end{array}$ & Teacher edition of student text & Not embedded & Explicit \\
\hline Biology: The Dynamics of Life (Biggs et al., 2005) & Teacher edition of student text & Not embedded & Explicit \\
\hline Biology: Living Systems (Biggs et al., 2003) & Teacher edition of student text & Not embedded & Explicit \\
\hline Biology (Miller \& Levine, 2006) & Teacher edition of student text & Not embedded & Explicit \\
\hline $\begin{array}{l}\text { Biology: A Community Context (Leonard \& Penick, } \\
\text { 2003) }\end{array}$ & Teacher guide & Embedded & Mixed \\
\hline Insights in Biology (EDC, 1998) & Teacher guide & Embedded & Mixed \\
\hline Biology: A Human Approach (BSCS, 2006a) & Teacher guide & Embedded & Not explicit \\
\hline
\end{tabular}


that were keyed to the student content were included in the analysis, that is, teacher editions of textbooks with wraparound text and teacher guides. Stand-alone materials not correlated to student content, such as laboratory manuals, were not coded but were described qualitatively. These ancillary materials usually did not contain teacher-learning supports as defined by the evaluation criteria.

\section{Evaluation Procedure}

Twenty-five evaluation criteria were used in this analysis. These criteria represented different types of support that were coded for in the materials. These evaluation criteria were derived from Davis and Krajcik's (2005) design heuristics for educative curriculum materials. These heuristics were informed by recommendations put forth by Ball and Cohen (1996) and Brown (2009) as well as by the limited empirical work that has been conducted on this topic (e.g., Collopy, 2003; Petish, 2004; Remillard, 2000; Schneider \& Krajcik, 2002). These evaluation criteria were grouped into nine categories, corresponding to the original nine design heuristics, and were operationalized in order to create parallel forms of support across the categories.

Within each category except Category $9,{ }^{1}$ evaluation criteria were organized around baseline features and encompassed two specific forms of support: rationales and implementation guidance. Baseline features are curricular components upon which educative supports are built. As noted above, implementation guidance is one form of educative support that helps teachers know how to use instructional approaches and activities in productive ways by making explicit their salient features. Implementation guidance also helps teachers adapt these approaches to achieve productive instructional ends (Davis \& Krajcik, 2005; Remillard, 2000; Schneider \& Krajcik, 2002). Rationale is a second form of support that presents explicit justification for using particular instructional approaches by explaining why these approaches are pedagogically and scientifically appropriate. This type of support is educative because it makes the curriculum developers' pedagogical and curricular decisions visible to teachers. Rationales provide opportunities for teachers to examine the assumptions and agendas underlying the instructional approaches embodied in the curriculum materials (Ball \& Cohen, 1996; Davis \& Krajcik, 2005; Remillard, 2000).

The nine categories were further grouped into three domains of teacher knowledge: teachers' subject matter knowledge, PCK for science topics, and PCK for scientific inquiry. These three domains were identified from the literature as important areas in need of support but were not intended to be exhaustive in coverage (Davis \& Krajcik, 2005). Support for PCK for science topics corresponded to three categories: support for teachers in engaging students with scientific phenomena, using scientific instructional representations, and anticipating and dealing with students' ideas about science. Support for PCK for scientific inquiry included five categories: support for teachers in engaging students in asking and answering questions, collecting and analyzing data, designing investigations, making evidence-based explanations, and communicating scientifically. Finally, support for teachers' subject matter knowledge corresponded to one category: support for teachers in developing their knowledge of content. Examples of support for each domain are provided in the Results Section. Table 2 lists the evaluation criteria as organized into the categories of support and teacher knowledge domains.

The second research question, concerning the quality of support for teachers, emerged during analysis, as reviewers noted important qualitative differences between materials. The evaluation criteria did not include a rating scheme or rubric with which to evaluate the quality of support; the criteria only indicated the presence or absence of a type of support. Therefore, the quality of the educative supports present in each set of materials was evaluated holistically and qualitatively, using rich description and analysis.

\section{Analysis}

Eight reviewers participated in this study. Reviewers included university faculty and graduate students - all with knowledge of the research on science learning and teaching, three with biology backgrounds, and two with former high school biology teaching experience. All reviewers independently evaluated their assigned set of teacher materials using the criteria outlined in Table 2 . The reviewers coded and recorded each instance of educative support found in the materials, and multiple codes were assigned to same passage, if relevant. After coding the materials, descriptive statistics were used to determine how often 
Table 2

Teacher knowledge domains and their respective categories and criteria

Domain/Category/Criteria

Form of Support

Domain: PCK for Science Topics

Category 1. Support Teachers in Engaging Students with Topic-Specific Scientific Phenomena

Provide physical (and vicarious) experiences for students

A. Explain why particular experiences are appropriate

B. Help teachers engage students in specific experiences

C. Warn of potential pitfalls with specific physical experiences

D. Help teachers think about productive activity sequences

Category 2. Support Teachers in Using Scientific Instructional Representations

Provide appropriate representations of scientific phenomena

A. Explain why particular representations are appropriate

B. Help teachers use particular representations with students

Category 3. Support Teachers in Anticipating and Dealing with Students' Ideas About Science
A. Explain why attending to students' ideas is important Rationale

B. Help teachers identify likely student ideas within a topic

C. Help teachers deal with their students' ideas in their teaching

Domain: PCK for Scientific Inquiry

Category 4. Support Teachers in Engaging Students in Questions

Provide questions to frame unit and questions for discussion

A. Explain why particular questions are appropriate

B. Help teachers use questions with students

C. Help teachers have students ask/answer their own questions

Category 5. Support Teachers in Engaging Students With Collecting and Analyzing Data
Suggest approaches for collecting and analyzing data

A. Explain why collection/analysis approaches are appropriate

B. Explain why evidence is essential to scientific inquiry

C. Help teachers use approaches for collecting and analyzing data

D. Help teachers use particular approaches for collecting and analyzing data across multiple topic areas

Category 6. Support Teachers in Engaging Students in Designing Investigations

Allow students to design their own investigations

A. Explain why designing their own investigations is important

B. Provide guidance for how teachers can support students in designing their own investigations

Category 7. Support Teachers in Helping Students Make Explanations Based on Evidence

Suggest approaches to help students construct explanations

A. Explain why explanation-building approaches are appropriate

B. Explain why explanation construction is essential to inquiry

C. Help teachers use specific approaches for constructing evidence-based explanations with their students

Category 8. Support Teachers in Promoting Scientific Communication

Provide approaches for promoting science communication

A. Explain why communication approaches are appropriate

B. Help teachers use particular communication approaches

Domain: Teacher's Subject Matter Knowledge

Category 9. Support Teachers in the Development of Subject Matter Knowledge

Help teachers develop their knowledge of science

A. Explain why having strong content knowledge is important

B. Present science content information that is beyond the level of

Baseline feature

Rationale

Implementation guidance

Implementation guidance

Implementation guidance

Baseline feature

Rationale

Implementation guidance

Implementation guidance

Implementation guidance

Baseline feature

Rationale

Implementation guidance

Implementation guidance

Baseline feature

Rationale

Rationale

Implementation guidance

Implementation guidance

Baseline feature

Rationale

Implementation guidance

Baseline feature

Rationale

Rationale

Implementation guidance

Baseline feature

Rationale

Implementation guidance

Baseline feature

Rationale

Other educative feature understanding required by students

each set of materials supported each domain of teacher knowledge. Patterns were then identified across materials with regard to the types and frequency of educative supports present. These patterns are reported in the Results Section. Comparisons among materials in terms of the frequency of different types of educative supports were also made. However, the results from these comparisons are only briefly mentioned because the purpose of this article is to inform the field's understanding of the strengths and weaknesses across existing 
curricular programs rather than on the specifics of individual programs. However, those interested in these comparisons can access the results elsewhere (Beyer, Delgado, Davis, \& Krajcik, 2006).

To complement the quantitative analysis, reviewers wrote descriptive narratives that characterized the quality of the most common educative supports found in each set of teacher materials. These narratives included a description of how each type of educative support supported teacher learning and where each could be found in the materials. The narratives also included excerpts that exemplified each type of support. The descriptive narratives generated by reviewers can be found in a previous report (Beyer et al., 2006). After developing these descriptions of the materials, we then examined the narratives for patterns in the quality of the educative supports across the eight sets of curriculum materials. These patterns emerged from the data analysis. Once patterns were identified, we tested their viability by seeking both confirming and disconfirming evidence and modified them as needed (Erickson, 1986).

\section{Reliability of Results}

Prior to the analysis, reviewers practiced jointly and independently applying the criteria to sections of text drawn from both NSF-funded and commercially developed materials, using topics other than the ones selected for the analysis. Reviewers then compared their results, developing a shared understanding of the criteria. During the actual evaluation process, additional discussions took place via face-to-face group meetings, email, and an on-line posting board. These discussions allowed reviewers to resolve any ambiguity as a group in the application of the criteria. An on-line record was kept during the training and subsequent analyses, documenting the clarifications made to the meaning of the evaluation criteria.

To further enhance the validity of our results, each person also served as a second reviewer on another set of materials. The different sets of curriculum materials were rotated among all eight reviewers. This system of rotation enabled us to obtain overlapping inter-rater reliability among all eight coders rather than between pairs of coders. The second reviewer independently evaluated a minimum of 10 pages on each topic (20\% of the data). Most reviewers achieved around $90 \%$ inter-rater reliability on at least $10 \%$ of the data (and typically on 20\%) and subsequently resolved all disputes through discussion. Reviewers of two of the curricular programs, Insights in Biology and BSCS Biology: A Human Approach, coded additional pages until they achieved a percent agreement on the selection that was equivalent to the other reviewers. Finally, the qualitative narrative descriptions characterizing each set of curriculum materials were written by the primary reviewer and examined by the secondary reviewer. Disagreements were resolved through discussion.

With regard to the representativeness of the results, slight differences may exist in the distribution of supports between the topics that were evaluated—evolution and ecology — and the rest of the topics. Had different topics been selected, the relative frequency of supports may have varied slightly. Also, for programs having fewer than 50 pages on a topic (EDC, 1998; Kaskel et al., 2003; Leonard \& Penick, 2003), the actual counts were extrapolated linearly from the actual number of pages to 50 pages. Thus, the frequencies reported may not be entirely representative of the actual frequencies if the materials were to have had 50 pages on each topic. With these considerations in mind, findings are summarized below and illustrated with examples from the curriculum materials.

\section{Results}

This section presents findings on the relative quantity of different types of educative supports across eight sets of curriculum materials. We first report on the relative frequency of supports across three teacher knowledge domains and then describe the relative frequency of different forms of support (rationales and implementation guidance). We conclude this section with a description of the quality of educative supports across curriculum materials.

Question 1a: What Is the Relative Frequency of Support for Teachers' Subject Matter Knowledge, PCK for Science Topics, and PCK for Inquiry?

As mentioned earlier, evaluation criteria focused on support for three teacher knowledge domains: teachers' subject matter knowledge, PCK for science topics, and PCK for scientific inquiry. Table 3 presents the total number of instances of educative support for each teacher knowledge domain across all eight curricular programs. 
Table 3

Frequency and percentage of support for teacher knowledge domains across programs

\begin{tabular}{lcc}
\hline Teacher Knowledge Domain & Frequency of Support & Percentage of Support \\
\hline PCK for topics & 318 & 55 \\
PCK for inquiry & 72 & 13 \\
Subject matter knowledge & 183 & 32 \\
Total & 573 & 100 \\
\hline
\end{tabular}

Support for PCK for science topics was the most prevalent domain of teacher knowledge supported in the materials, accounting for $55 \%$ of all instances of educative support. The next most common support was for teachers' subject matter knowledge (32\% of all support) followed by PCK for scientific inquiry (13\% of all support). A further breakdown by category and criterion follows, along with illustrative examples.

Support for PCK for Science Topics (Categories 1-3)

PCK for science topics was the most common knowledge domain supported in the programs, representing 55\% of all instances of support in the materials. Support for PCK for topics entails guidance for teachers in three categories: engaging students with topic-specific phenomena (Category 1), using instructional representations (Category 2), and anticipating and dealing with students' ideas about science topics (Category 3). Table 4 presents the frequency and percentages of support by category and criterion for this domain of teacher knowledge.

Within PCK for science topics, support for attending to students' ideas was the most common category of support (Category 3,50\% of all instances of educative support within this domain), followed by support for using phenomena (Category 1,27\%) and representations (Category 2, 23\%). Each of these categories is further described below with examples.

Category 1-Supporting Teachers in Using Scientific Phenomena. Over a quarter (27\%) of the educative supports coded for PCK for topics came from Category 1 (see Table 4). The most common type of support within this category was rationales for engaging students in real-world phenomena, comprising $12 \%$ of the total instances coded within PCK for topics. An example of this type of support includes the following rationale, which explains why teachers might want to have students examine live specimens using a microscope or hand lens in their investigation:

Table 4

PCK for topics: frequency and percentage of support by criterion across programs

\begin{tabular}{lccc}
\hline Category/Criterion & $\begin{array}{c}\text { Frequency of } \\
\text { Support }\end{array}$ & $\begin{array}{c}\text { \% of Support Within } \\
\text { PCK for Topics }\end{array}$ & $\begin{array}{c}\% \text { of Support } \\
\text { Across Domains }\end{array}$ \\
\hline 1. Support Teachers in Using Scientific Phenomena & & & 7 \\
A. Rationale for using specific phenomena & 38 & 12 & 4 \\
B. Guidance on using specific phenomena & 23 & 7 & 4 \\
C. Guidance on pitfalls with specific phenomena & 23 & 7 & 1 \\
D. Guidance on sequences of tasks for phenomena & 3 & 1 & 15 \\
$\quad$ Total Across Programs & 87 & 27 & 5 \\
2. Support Teachers in Using Representations & 26 & 8 & 8 \\
A. Rationale for using specific representations & 46 & 14 & 13 \\
B. Guidance on using specific representations & 72 & 23 & 1 \\
$\quad$ Total Across Programs & & & 17 \\
3. Support Teachers in Regards to Students' Ideas & 5 & 2 & 10 \\
A. Rationale for attending to students' ideas & 99 & 31 & 28 \\
B. Guidance on identifying students' ideas & 55 & 17 & 55 \\
C. Guidance on dealing with students' ideas & 159 & 50 & \\
$\quad$ Total Across Programs & 318 & 100 & \\
Total Support for PCK for Topics Across Programs & & & \\
\hline
\end{tabular}

Percentages may not add up to totals due to rounding. 
This investigation allows students to sharpen their observational skills while working with a variety of organisms. Positioned at the beginning of the chapter, the investigation sets the stage for discussing the web of life. (BSCS, 2006b, p. 20)

This excerpt exemplifies the type of support that teachers commonly received when they were provided with opportunities to engage students in real-world phenomena.

Category 2-Supporting Teachers in Using Representations. Twenty-three percent of the educative supports coded for PCK for topics consisted of support for teachers in using instructional representations (see Table 4). Support within this category often took the form of recommendations that aimed to help teachers effectively use specific representations described in the materials. This type of implementation guidance comprised $14 \%$ of the total instances coded within PCK for topics. The following excerpt illustrates this type of support by explaining to teachers how they might use a photograph in the textbook to illustrate interactions between biological and physical factors in an ecosystem:

Understanding the Photo. Provide students with the opportunity to discuss what the bird is doing. Cedar waxwings like the high sugar content of ripening fruit (in this case, Mountain ash berries). Ask students what clues this fact might give them about when the bird will be most visible. Summer into early fall when fruit is ripe. As you develop the concepts of biotic and abiotic factors, use this photo to make these concepts more real. The bird and the ripening fruit are biotic factors. The time of year, controlled by light and climate, is an abiotic factor that affects the time food is available to the bird. Later in the chapter, have students write or discuss how the photograph sums up the big picture of ecology. (Biggs et al., 2005, p. 34)

This excerpt aims to help teachers effectively use this representation by pointing out the salient features of the photo and providing suggestions for its use. This typical example shows the type of support that most materials provided teachers with regard to helping them use representations.

Category 3-Supporting Teachers in Regards to Students' Ideas. Half of all instances of educative support coded within PCK for topics corresponded to Category 3. Within this category, support for helping teachers identify students' ideas and deal with those ideas in their instruction were two common types of support, constituting 31\% and 17\% of all instances coded within PCK for topics, respectively (see Table 4). These percentages show that only half of the educative features that helped teachers identify students' ideas also gave guidance for how to deal with them. Additionally, across all three teacher knowledge domains, these supports were the second and third most frequently encountered in the curriculum materials. The following excerpt highlights an example of support for identifying and dealing with students' ideas:

Some students may have the misconceptions that all areas in tropical regions receive a great amount of rainfall all the time. Explain that it is true that many areas have abundant rainfall because of frequent thunderstorms caused by local heating of the air. Currents in the atmosphere, however, are extremely complex, and in some regions wind patterns result in much less precipitation than is found in regions with tropical rain forests. The result is that the tropics contain dry forests, savannas, and even deserts. (Miller \& Levine, 2006, p. 100)

This passage supports teachers by alerting them to a common alternative idea and suggests a strategy for remediation: that teachers tell students the correct scientific idea.

While the example above presents possible student ideas directly to the teacher, the next example illustrates how some supports guided teachers in determining their own students' ideas.

Discussion Questions: This discussion should give you an opportunity to determine student preconceptions and their current level of understanding. To facilitate this discussion you may wish to ask the following:

- What is a habitat? What are some examples?

- What is an ecosystem? What are some examples? 
- What are some of the features and/or components of an ecosystem?

- Why is Earth itself considered an ecosystem? (EDC, 1998, What on Earth? module, p. 4)

Questions of this type were common, although in some cases the purpose of the questions was left unstated. In sum, support for identifying and dealing with students' ideas was frequent and took several different forms. The quality of the different types of support for attending to students' ideas is addressed further in the results for research question 2 .

\section{Support for Teachers' Subject Matter Knowledge (Category 9)}

Teachers' subject matter knowledge was the second most commonly supported domain of teacher knowledge in the materials, after PCK for topics, accounting for $32 \%$ of all educative support (see Table 3 ). This domain consisted of only one category, that is, support for teachers' subject matter knowledge (Category 9). The most common type of support within this category was providing teachers with science content information beyond the level of understanding required by students. Across all three teacher knowledge domains, this criterion was the most frequently encountered in the curriculum materials, constituting nearly one-third of all educative supports. On the other hand, rationales for the importance of strong teacher content knowledge were almost entirely absent from the materials. Table 5 presents the frequency and percentages of support by criterion for this domain of teacher knowledge.

Support for teachers' subject matter knowledge commonly entailed additional information related to ideas in the student text. An example of this type of support reads:

Any chlorophyll-containing organism can use light energy to make its own food. Much of the photosynthesis on the earth is carried out by algae and cyanobacteria. The discussion here is limited to green plants for simplicity. (BSCS, 2006b, p. 93)

This example provides teachers with the opportunity to develop a deeper understanding of photosynthesis discussed in the student materials. Most instances provided teachers with additional information but did not explicitly state how ideas in the student textbook had been simplified, as the example above states.

\section{Support for PCK for Scientific Inquiry (Categories 4-8)}

PCK for scientific inquiry was the teacher knowledge domain that received the least amount of support across all the materials, accounting for only $13 \%$ of the total support (see Table 3). Support for PCK for inquiry entailed helping teachers engage students in asking and answering scientific questions (Category 4), collecting and analyzing data (Category 5), designing investigations (Category 6), making explanations based on evidence (Category 7), and communicating scientifically (Category 8). Table 6 presents the frequency and percentages of support by category and criterion for this domain of teacher knowledge.

Within PCK for inquiry, support for promoting scientific communication was most commonly coded (Category 8, 43\% of all instances of educative support within this domain), followed by support for engaging students in asking and answering scientific questions (Category 4,35\%). Across all eight sets of curriculum

Table 5

Subject matter knowledge: frequency and percentage of support by criterion across programs

\begin{tabular}{lccc}
\hline Category/criterion & $\begin{array}{c}\text { Frequency of } \\
\text { Support }\end{array}$ & $\begin{array}{c}\% \text { of Support for Subject } \\
\text { Matter Knowledge }\end{array}$ & $\begin{array}{c}\text { \% of Support } \\
\text { Across Domains }\end{array}$ \\
\hline 9. Support Teachers in Learning about Science & & & $<1$ \\
A. Rationale for developing content knowledge & 1 & 1 & 32 \\
B. Science background knowledge for teachers & 182 & 99 & 32 \\
Total Support Across Programs & 183 & 100 & \\
\hline
\end{tabular}


Table 6

PCK for inquiry: frequency and percentage of support by criterion across programs

\begin{tabular}{lccc}
\hline \multirow{2}{*}{ Category/Criterion } & Frequency of & $\%$ of Support Within & $\%$ of Support \\
& Support & PCK for Inquiry & Across Domains \\
\hline
\end{tabular}

4. Support Teachers in Engaging Students in Questions

A. Rationale for using particular questions

B. Guidance on using particular questions

C. Guidance on having students use their questions Total Across Programs

5. Support Teachers in Fostering Data Collection/Analysis

A. Rationale for data collection/analysis strategies

B. Rationale for having students collect data

C. Guidance on using specific approaches

D. Guidance on using specific data collection and analysis approaches across multiple topic areas Total Across Programs

6. Support Teachers in Helping Students Design Investigations

A. Rationale for having students design studies

B. Guidance on having students design studies Total Across Programs

7. Support Teachers in Engaging Students in Explanations

A. Rationale for using approaches for explanations

B. Rationale for fostering explanation construction

C. Guidance on using approaches for explanations Total Across Programs

8. Support Teachers in Promoting Scientific Communication

A. Rationale for using communication approaches

B. Guidance on using communication approaches Total Across Programs

Total Support for PCK for Inquiry Across Programs

\begin{tabular}{|c|c|c|}
\hline 21 & 29 & 4 \\
\hline 1 & 1 & $<1$ \\
\hline 3 & 4 & 1 \\
\hline 25 & 35 & 4 \\
\hline 2 & 3 & $<1$ \\
\hline 2 & 3 & $<1$ \\
\hline 3 & 4 & 1 \\
\hline 0 & 0 & 0 \\
\hline 7 & 10 & 1 \\
\hline 2 & 3 & $<1$ \\
\hline 4 & 6 & 1 \\
\hline 6 & 8 & 1 \\
\hline 0 & 0 & 0 \\
\hline 0 & 0 & 0 \\
\hline 3 & 4 & 1 \\
\hline 3 & 4 & 1 \\
\hline 16 & 22 & 3 \\
\hline 15 & 21 & 3 \\
\hline 31 & 43 & 5 \\
\hline 72 & 100 & 13 \\
\hline
\end{tabular}

Percentages may not add up to totals due to rounding.

materials, only seven or fewer instances of support were found for each of the remaining categories. The two more common categories ( 4 and 8 ) are further described below. Given the infrequency of these supports, the illustrative excerpts should be viewed as exemplars rather than as typical examples.

Category 4-Supporting Teachers in Engaging Students in Questions. In Category 4, the most common type of support was rationales for using the questions provided in the teacher materials and consisted of $29 \%$ of the total support within PCK for inquiry (see Table 6). The following exemplar illustrates how some curriculum materials provided teachers with explicit justification for the use of specific questions during instruction:

Ask students to imagine what would happen if any one or two of these types of workers disappeared. This question is intended to get students thinking about the consequences of an extinction event. (EDC, 1998, What on Earth? module, p. 23)

This excerpt helps teachers understand why they might want to ask students certain questions during instruction, thereby supporting teachers in engaging students in using questions.

Category 8-Supporting Teachers in Promoting Scientific Communication. The two criteria in Category 8 were equally common in the curriculum materials (see Table 6). Support for promoting scientific talk included helping teachers understand why suggested approaches for fostering communication were scientifically and pedagogically appropriate and comprised $22 \%$ of the total support within PCK for inquiry. An example of this support includes the following explanation stating why teachers might want to use a particular strategy for a team project: 
The story can be written as a team project by having each student write about how one of the scientific disciplines would work with the fossil find. You may want to add the requirement that the specialist may not write about his or her own evidence. This strategy will ensure that the students convey their information to their teammates and that they are able to learn from each other. (BSCS, 2006a, p. 73)

This excerpt provides teachers with explicitly stated reasons for the suggested communication approaches, thereby facilitating teachers' learning about this aspect of inquiry-oriented teaching.

The other type of support within this category consisted of guidance for teachers in implementing and adapting communication approaches with their students. For example, one program encouraged teachers to have students work in groups as they completed an activity (a common suggestion in the curriculum materials) but then also provided guidance on how to help students engage in productive conversations as they worked in these groups. It reads,

Have the students in each team concentrate on listening to and respecting each other's ideas. Make clear to the students that this is one goal of the activity. You might decide to write "Listen to your teammates" on the board as a reminder. As the activity proceeds, keep track of how well the students are listening to each other. If a team seems to be having trouble with one or two dominant individuals, model the types of questions and etiquette expected of the dominant individuals by asking another team member. What ideas do you have about how this event should be placed? (BSCS, 2006a, p. 66)

This example provides detailed suggestions for teachers in fostering productive conversations during group work, helping teachers learn how to engage students in scientific communication.

\section{Summary of Support Across Teacher Knowledge Domains}

In sum, PCK for topics was the most commonly supported teacher knowledge domain, and within this domain, supports for identifying and working with students' ideas about science were the two most prevalent types of support. Support for teachers' subject matter knowledge was the next most frequently supported domain, and providing teachers with science content information was the most common type of support within this domain and in the materials, overall. Support for PCK for inquiry was the least frequently supported domain and was generally low across all five categories. Two NSF-funded curriculum materials, BSCS Biology: A Human Approach (BSCS, 2006a) and Insights in Biology (EDC, 1998), differed notably from the other programs. They had the most support for PCK for inquiry, 40 and 19 instances of support, respectively, in the sampled materials in comparison to five or fewer instances of support in the other programs. Additionally, these two programs provided the most support for teachers across all categories of support, providing over 100 instances of support in the sampled materials, in contrast to an average of 57 instances of support in the other programs. These findings and others dealing with comparisons among materials are further discussed elsewhere (Beyer et al., 2006).

\section{Question 1b: What Is the Relative Frequency of Rationales and Implementation Guidance?}

In addition to examining the frequency of support across the three teacher knowledge domains, the form of support (implementation guidance vs. rationale) was also examined. Implementation guidance helps teachers know how to use suggested instructional approaches and activities in productive ways. Rationales present explicit justification for including the instructional approaches in the curriculum by explaining why they are pedagogically and scientifically appropriate. Across the eight sets of curriculum materials, implementation guidance was by far more prevalent than rationales. Implementation guidance comprised $48 \%$ of the total instances of support coded, while rationales accounted for only $20 \%$. (Subject matter support for teachers [Category 9B], which was classified neither as rationale or implementation guidance, made up the remaining 32\% of support.) Table 7 presents the total instances of educative support for each form of support across the entire data corpus analyzed.

These findings show that the curriculum materials tended to provide more support for how to use or adapt particular instructional approaches than for why these approaches might be useful in practice. Thus, there 
Table 7

Frequency and percentage of support for different forms of support across programs

\begin{tabular}{lcc}
\hline Form of Support & Frequency of Support & Percentage of Support \\
\hline Implementation guidance & 277 & 48 \\
Rationale & 113 & 20 \\
Subject matter support & 183 & 32 \\
Total & 573 & 100 \\
\hline
\end{tabular}

were relatively few supports enabling teachers to examine the assumptions and agendas underlying the approaches embodied in the curriculum materials.

With regard to rationales, one set of materials supported teachers in using a compost column to help students explore a small-scale ecosystem by explaining why having students experience this phenomenon was important. It reads:

Studying composting can lead to understanding the relationship between biology and energy transfer in the environment. This activity also provides a solid example of how individuals can have a positive effect on the environment while decreasing the amount of water. (Leonard \& Penick, 2003, p. 48)

The materials also included implementation guidance to help teachers use this phenomenon with their class. For example, in helping students use the columns to study producers, consumers, and decomposers, the materials explained how to find these organisms in the columns. It reads,

Finding creatures in the compost can be aided in several ways. Putting the compost in a white enamel pan and then separating the material is one way to make it easy to see the larger animals. An old technique for separating the organisms from the compost is a funnel with a heat source above and a container... (Leonard \& Penick, 2003, p. 135)

These excerpts highlight examples of both rationales and implementation guidance support found in the materials. However, curriculum materials typically provided far fewer opportunities for teachers to see why specific approaches might be useful than to understand how to use the instructional approaches in their practice.

\section{Question 2: What Is the Quality of Educative Supports Across Curriculum Materials?}

The quantity of support was not the only consideration in determining the materials' potential for promoting teacher learning. The quality of support was also an important consideration, particularly since it differed among the materials. The quality of the most common types of support for each set of materials was described in the narrative reports. The quality of these supports is described below with illustrative examples drawn from the teacher materials.

The curriculum materials exhibited a range of support that varied along several dimensions. The educative supports in the materials varied in their degree of relevance for teachers. Relevance here refers to the applicability of the educative supports to key science concepts described in national standards documents (AAAS, 1993; NRC, 1996), as opposed to small details or unimportant facts. The supports also differed in regard to their degree of pedagogical helpfulness. Pedagogical helpfulness here refers to the extent to which teachers were provided with effective and reliable guidance as evidenced by research and teacher experience (e.g., suggestions of questions to scaffold students' scientific understanding). Additionally, programs contained support that varied in its degree of depth. Depth here refers to how thoroughly the supports developed ideas and detailed connections among them (e.g., providing a detailed description of an instructional strategy and explaining how the strategy connects to the promotion of student learning). Excerpts demonstrating this range of support for three of the most commonly coded criteria—support for teachers' subject matter knowledge and knowledge of students' ideas and how to deal with them-are presented and discussed below. 


\title{
Support for Teachers' Subject Matter Knowledge
}

With regard to support for teachers' subject matter knowledge, one program provided over a page of detailed, relevant information pertaining to the characteristics of a population, types of growth curves, and the effects of population size, carrying capacity, and growth rates (Leonard \& Penick, 2003, p. 177). This educative support provided teachers with relevant, in-depth support by thoroughly elaborating upon the core science concepts included in standards documents (AAAS, 1993; NRC, 1996) and thus was potentially pedagogically helpful for teachers.

In contrast, the following excerpt on factors impacting population size provided teachers with less indepth support:

\begin{abstract}
Animal population size can be influenced by amount of food and space available. Natural populations cannot increase forever; population size is also controlled by environmental and biological factors. Animals immigrating to one area are emigrating from another area. A chief factor influencing the size of a plant population is the amount to daily sunlight and the space available in which roots can grow and spread. (Kaskel et al., 2003, p. 632)
\end{abstract}

This typical passage shows that in supporting teachers' content knowledge, some materials provided only brief snippets of support and lists of disconnected facts. Other subject matter knowledge supports for teachers not only lacked depth but were also unrelated to key ideas representing important science concepts (AAAS, 1993; NRC, 1996). Therefore, even though support for teachers' subject matter knowledge was the most frequent type of support in the materials, it varied in its degree of depth and relevance and thus its pedagogical helpfulness.

\section{Support for Teachers' Knowledge of Students' Ideas}

Other examples illustrating the variation in quality of support include supports designed to help teachers attend to students' likely ideas about science. Many materials helped teachers identify their students' ideas by alerting them to common misconceptions. Some misconceptions were related to central concepts (AAAS, 1993; NRC, 1996) and were thoroughly described and thus were potentially pedagogically helpful, such as, "Students may not understand that all living things in a community are important in the food web. They may regard mice and snakes as undesirable or useless animals" (Kaskel et al., 2003, p. 631). However, other excerpts highlighting common student misconceptions were less useful, including, "A popularly held misconception is that large groups of lemmings, a small arctic mammal, periodically march into the ocean in mass suicides, thus reducing their large population" (Biggs et al., 2005, p. 76), and "Misconception. Unlike the ferocious monster plants highlighted by commercial horror movies, the insectivorous plants of bogs in the taiga are generally small” (Biggs et al., 2003, p. 825).

\section{Support for Teachers' Knowledge of Instructional Strategies for Dealing With Students' Ideas}

In addition to providing a range of relevant support for anticipating students' ideas, curriculum materials contained a range of support for dealing with those ideas, varying in their degree of depth and pedagogical helpfulness. Most programs instructed teachers to simply tell students the correct scientific answer-an approach not likely to foster student understanding (Bransford, Brown, \& Cocking, 1999), and thus not very pedagogically helpful. For example, one material reads, "The following statement is often heard from students. 'Humans evolved from apes.' Advise students that evolutionary evidence supports the theory that humans and apes evolved from a common early ancestor" (Kaskel et al., 2003, p. 605). This typical excerpt shows that some supports were extremely limited in depth and questionable in effectiveness, providing minimal guidance for teachers. Other supports for teachers not only lacked depth and pedagogical helpfulness but also relevance to key science concepts in standards documents (AAAS, 1993; NRC, 1996).

In contrast, some materials included in-depth, relevant, and pedagogically helpful support by thoroughly describing useful strategies. For example, the excerpt below includes a more thorough discussion of how a teacher might deal with the same misconception described above: 
Revealing Misconceptions: "If humans evolved from apes, why are there still apes alive today?" is a question often posed by students. The question represents a common misconception that students have about human evolution.

Uncover the Misconception: Explain that humans evolved from ancestors of apes, which were neither humans nor apes, and the common ancestor probably lived during the Miocene.

Demonstrate the Concept: Use an example from the previous chapter to explain the concept of common ancestry. You might use an example from the Galapagos Islands, or divergent evolution of the honeycreepers in Hawaii.

Assess New Knowledge: Ask students to suggest other examples of species that are closely related and what their common ancestor may have been. Have them suggest how they might explain this to a friend. (Biggs et al., 2005, p. 431)

This extensive discussion provides useful guidance about how teachers might foster student learning about evolution, illustrating an example of pedagogically helpful, relevant, and in-depth support for dealing with students' ideas about science.

In sum, the quantitative results were not the only indicator of the quality of the curriculum materials in terms of their teacher educativeness. Qualitative results also showed that the materials exhibited a range of relevant, pedagogically helpful, and in-depth support.

\section{Summary and Discussion}

The results of this study highlight the strengths, limitations, and gaps in teacher learning supports within existing curriculum materials. The high school biology curricular programs reviewed in this study included a variety of educative supports targeting multiple domains of teacher knowledge, but they did not support all domains equally. Materials tended to provide abundant support for teachers' subject matter knowledge as well as their understanding of students' likely ideas about science and how to address them-important aspects of PCK for science topics (Abell, 2007; Magnusson et al., 1999). However, the materials tended to include far less support for other categories within PCK for science topics, including helping teachers engage students in scientific phenomena and use instructional representations. The curricular programs also provided little support for all aspects of PCK for scientific inquiry, which included teachers' knowledge for engaging students in asking and answering scientific questions, designing investigations, collecting and analyzing data, making evidence-based explanations, and communicating scientifically (Davis \& Krajcik, 2005; Petish, 2004; Zembal-Saul \& Dana, 2000). This latter finding is unsurprising as we observed that most of the programs provided students with few opportunities to learn science through inquiry, and consequently, provided teachers with few chances to learn how to foster an inquiry-oriented learning environment.

In examining the quantity of different forms of support, this study found that the curriculum materials tended to have more than twice as much implementation guidance support than rationales. This means that the materials provided more support for helping teachers understand how they might use particular strategies described in the materials than why they might want to use them. Researchers argue that developers need to provide opportunities for teachers to examine the assumptions and reasons underlying curricular suggestions and make sense of tasks inspired by reform recommendations (Ball \& Cohen, 1996; Davis \& Krajcik, 2005; Remillard, 2000; Schneider, 2006). Curriculum materials that include such opportunities can help teachers not only understand how to support student learning but also why they might want to use specific strategies or tasks to foster that learning (Beyer \& Davis, in press; Petish, 2004), yet these materials, in general, did not provide such support.

Additionally, with regard to the quality of support, the curriculum materials exhibited a range in terms of their degree of relevance to the core concepts in the student materials, pedagogical helpfulness, and depth and comprehensiveness. Other curriculum reviews have found a similar trend in the quality of supports for student learning; they show that many existing science materials provide students with inadequate representations of the nature of science (Abd-El-Khalick et al., 2008) as well as guidance unrelated to core science concepts and fragmented support (AAAS, 2005; Hubisz, 2003; Kesidou \& Roseman, 2002; Stern \& Roseman, 2004).

Despite the range in the quantity and quality of support across materials, BSCS Biology: A Human Approach (BSCS, 2006a) and Insights in Biology (EDC, 1998) consistently provided more support for teachers than any other materials, including the popular commercial texts (Beyer et al., 2006). The qualitative 
analyses also revealed that many of the supports within these two materials were in-depth, pedagogically helpful, and relevant for teachers, as illustrated with examples throughout this article. These findings are similar to Project 2061's recent evaluation of high school biology textbooks, which found that these two programs ranked highest, according to their own evaluation criteria (AAAS, 2005; see Average of Ratings for Four Topics Table).

The findings from this study are drawn from our analysis of only two topics in the curricular programs: ecology and evolution. Thus, it is possible that additional strengths or weaknesses in the curriculum materials may have been identified if other topics of study had been chosen. However, we argue that the authors of these curricular programs likely implemented similar amounts and quality of support for teachers and students for all topics of study and thus suggest that the results reported here are likely to be similar for other topics found in the curriculum materials.

\section{Implications}

Many existing high school biology curricular programs do not provide adequate support for developing teachers' knowledge of content and pedagogy. This finding must be considered in light of the fact that the materials examined in this study predated the design heuristics that guided our analysis (Davis \& Krajcik, 2005) and were not necessarily designed with focused attention on teacher learning. Nonetheless, teachers still need opportunities to learn about and adopt new ways of teaching science. Therefore, in the meantime as teachers must use their existing materials, school districts may need to provide teachers with other professional development opportunities. This may include face-to-face summer workshops, on-line discussion boards, or ongoing support during the school year (Ball \& Cohen, 1996; Hewson, 2007; LoucksHorsley, Hewson, Love, \& Stiles, 1998; Putnam \& Borko, 2000). These opportunities may help teachers compensate for weaknesses and gaps in support within their materials. In addition, curriculum materials cannot single-handedly change the status quo in science classrooms; thus, complementing them with other forms of support may be more effective at helping teachers develop expertise in science teaching (Ball \& Cohen, 1996; Putnam \& Borko, 2000; Schneider \& Krajcik, 2002). Additionally, because existing curriculum materials provide few rationales for helping teachers understand developers' pedagogical decisions, another near-term solution may be to help preservice teachers learn how to examine the assumptions and agendas underlying curriculum materials. This may help them see written materials as adaptive resources and begin to make informed decisions about how to use existing curriculum materials in their own classrooms.

In addition to finding ways to support teachers' use of existing curriculum materials, we also provide recommendations for curriculum development, based on the evaluation criteria from this study and resultant findings that highlight the weaknesses and gaps within materials. First, in order to address gaps in support with regard to specific aspects of teacher knowledge, we suggest that existing curricular programs need to include more support for some facets of PCK for science topics. Specifically, developers need to help teachers use instructional representations and engage their students in scientific phenomena. Providing such support may help teachers develop their knowledge and abilities for teaching science (Beyer \& Davis, in press; Petish, 2004; Schneider, 2006; Schneider \& Krajcik, 2002). To address other gaps in existing curriculum materials and attend to crucial science education standards (NRC, 1996, 2000), materials need to include more inquiryoriented activities for students, and in turn, more support for all aspects of teachers' PCK for scientific inquiry. Such support can help teachers understand the importance of scientific inquiry and how to engage their students effectively in inquiry practices (McNeill \& Krajcik, 2008; Petish, 2004; Schneider, 2006; Schneider et al., 2005).

Second, in providing different forms of support for teachers, we suggest that curriculum developers need to more consistently provide rationales for teachers in the design of materials. This may help teachers examine the assumptions underlying particular instructional approaches and curricular suggestions described in the materials (Beyer \& Davis, in press; Petish, 2004).

Third, in order to address weaknesses in the quality of support across all teacher knowledge domains, we recommend that curriculum developers include stronger examples of support that are relevant, pedagogically useful, and sufficiently in depth. Specifically, with regard to the most common types of support found in this analysis, support for teachers' subject matter knowledge may be improved by providing more in-depth and relevant information rather than brief snippets and extraneous facts. Additionally, curriculum materials may 
better support teachers' knowledge of alternative science ideas and how to deal with them-one aspect of PCK for science topics (Abell, 2007; Magnusson et al., 1999)_by highlighting common student misconceptions that are relevant to key science concepts. They may also better support teachers by including pedagogically helpful strategies for addressing students' misconceptions rather than instructing teachers to simply tell students the "right answer."

Finally, some of the educative features within existing materials can provide developers with high quality examples of support. In particular, supports within BSCS Biology: A Human Approach (BSCS, 2006a) and Insights in Biology (EDC, 1998) stood above the rest in terms of the quality of guidance that they provided for teachers. Even though these two curricular programs have a small market share $(<2 \%$ in 2000 ; Weiss et al., 2001) and still have room for improvement (AAAS, 2005), these NSF-funded materials may serve as exemplars to inform the design of curriculum materials (St. John, 2002, as cited in Confrey \& Stohl, 2004) as well as guide textbook adoption decisions made by local school districts.

As curriculum developers consider these recommendations, they will need to continue to negotiate two fundamental tensions. First, they will need to consider how to provide support for a diverse array of teachers (Brown, 2009; Davis \& Krajcik, 2005). Teachers with varying amounts of teaching experience and familiarity with inquiry teaching may require different types and amounts of support. For example, teachers with extended experience teaching the same topic and in-depth knowledge of reform-oriented teaching practices may need less guidance in interpreting students' responses to particular questions or in using particular instructional representations that they have used in the past. Second, curriculum developers will need to consider how to address teachers' need for support without inundating them with too much information (Davis \& Krajcik, 2005). Determining the appropriate amount of guidance is important because teachers often do not have time to read everything in the curriculum materials. Additionally, teachers need room to draw upon their own personal resources to make productive changes and local adaptations to materials (Barab \& Luehmann, 2003; Pintó, 2004; Remillard, 2000). These tensions may be amenable to empirical research seeking to establish rules of thumb that can guide these decisions. Investigating the affordances of electronic media may also begin to address these tensions, by enabling teachers to select only the supports they need.

While this study sheds light on some of the strengths, weaknesses, and gaps in existing biology curriculum materials, additional studies are needed. Researchers have begun to describe the role of educative materials in shaping teacher knowledge and practice (Beyer \& Davis, in press; Collopy, 2003; McNeill \& Krajcik, 2008; Petish, 2004; Schneider, 2006; Schneider \& Krajcik, 2002). However, additional research is needed, especially research investigating the affordances and constraints of targeting specific aspects of teacher knowledge and using different types of educative supports in promoting teacher learning. Researchers have also started to examine the impact of the high school biology programs in promoting teacher learning (Gess-Newsome et al., 2008; Powell \& Gess-Newsome, 2008), but additional studies are needed. Additionally, while this study provides insights into the quantity and quality of educative supports in high school biology curriculum materials, other studies are needed to better understand how these findings compare with other curriculum materials written for different grade levels and science disciplines. Finally, researchers need to develop a more comprehensive evaluation protocol for examining how well existing curriculum materials help teachers learn about content and pedagogy, and in turn, test its reliability. Researchers need to include criteria targeting a wider range of teacher knowledge domains, such as knowledge of science curriculum, assessment of scientific literacy, and culturally responsive teaching (Abell, 2007; Gay, 2000; Magnusson et al., 1999). They also need to develop indicators and rating systems for judging how well curriculum materials meet each criterion.

In conclusion, this study contributes to the literature on curriculum evaluation and teacher learning supports. It helps the field discern the affordances and constraints of existing science curriculum materials in promoting teacher learning, and in turn, may provide insight into how such materials may be improved for teachers meeting ambitious learning goals and enacting reform practices.

\section{Note}

${ }^{1}$ All nine categories contained these two forms of support, except Category 9, which lacks a criterion dealing with implementation guidance. Implementation guidance is not applicable for supporting teachers' subject matter knowledge, 
since the additional content information intended to support teacher learning is not implemented in the classroom. Additionally, criterion 9B, which deals with providing teachers with science content information, does not fall under either rationale or implementation guidance.

This work was funded by the National Science Foundation under Grant No. ESI-0455846. However, any opinions, findings, and conclusions or recommendations expressed in this material are those of the authors. We greatly appreciate the assistance of Nonye Alozie, Shannon Dalpe, Jay Fogleman, Cory Forbes, and Joi Merritt in helping review the curriculum materials for this study. We also thank the members of the Center for Curriculum Materials in Science for their thoughtful feedback.

\section{References}

Abd-El-Khalick, F., Waters, M., \& Le, A. (2008). Representations of nature of science in high school chemistry textbooks over the past four decades. Journal of Research in Science Teaching, 45(7), 835855 .

Abell, S.K. (2007). Research on science teacher knowledge. In: S.K. Abell \& N.G. Lederman (Eds.), Handbook of research on science education (pp. 1105-1149). Mahwah, NJ: Lawrence Erlbaum Associates.

American Association for the Advancement of Science. (1993). Benchmarks for science literacy. New York: Oxford University Press.

American Association for the Advancement of Science. (2005). High school biology textbooks: A benchmarks-based evaluation. Retrieved February 2, 2007, from http://www.project2061.org/publications/ textbook/hsbio/report/browse.htm.

Ball, D.L., \& Cohen, D.K. (1996). Reform by the book: What is—or might be—the role of curriculum materials in teacher learning and instructional reform? Educational Researcher, 25(9), 6-8, 14.

Ball, D.L., \& Feiman-Nemser, S. (1988). Using textbooks and teachers' guides: A dilemma for beginning teachers and teacher educators. Curriculum Inquiry, 18, 401-423.

Barab, S.A., \& Luehmann, A.L. (2003). Building sustainable science curriculum: Acknowledging and accommodating local adaptation. Science Education, 87, 454-467.

Beyer, C.J., \& Davis, E.A. (in press). Supporting preservice elementary teachers' critique and adaptation of science curriculum materials using educative curriculum materials. Journal of Science Teacher Education.

Beyer, C.J., \& Davis, E.A. (in press). Using educative curriculum materials to support preservice elementary teachers' curricular planning: A comparison between two different forms of support. Curriculum Inquiry.

Beyer, C.J., Delgado, C., Davis, E.A., \& Krajcik, J.S. (2006). Investigating high school biology texts as educative curriculum materials: Curriculum review process (Evaluation Report). Ann Arbor, MI. Available at http://hice.org/papers/index.html.

Biggs, A., Hagins, W.C., Kapicka, C., Lundgren, L., Rillero, P., Tallman, K.G., \& Zike, D., National Geographic Society. (2005). Biology: The dynamics of life. New York: Glencoe/McGraw-Hill.

Biggs, A., Kaskel, A., Lundgren, L., \& Mathieu, D. (2003). Biology: Living systems. New York: Glencoe/McGraw-Hill.

Biological Sciences Curriculum Study (BSCS). (2006a). BSCS biology: A human approach. (3rd ed.) Dubuque, IA: Kendall/Hunt Publishing Company.

Biological Sciences Curriculum Study (BSCS). (2006b). BSCS Biology: An ecological approach. (10th ed.) Dubuque, IA: Kendall/Hunt Publishing Company.

Borko, H., \& Putnam, R.T. (1996). Learning to teach. In: D.C. Berliner (Ed.), Handbook of educational psychology. New York, NY: Macmillan.

Bransford J.D. Brown A.L. Cocking R.R. (Eds.), (1999). How people learn: Brain, mind, experience, and school. Washington, DC: National Academy Press.

Brown, M.W. (2009). The teacher-tool relationship: Theorizing the design and use of curriculum materials. In J.T. Remillard, B.A. Herbel-Eisenmann, \& G.M. Lloyd (Eds.), Mathematics teachers at work: Connecting curriculum materials and classroom instruction (pp. 17-36). New York, NY: Routledge. 
Brown, M., \& Edelson, D. (2003). Teaching as design: Can we better understand the ways in which teachers use materials so we can better design materials to support their changes in practice? (Design Brief). Evanston, IL: Center for Learning Technologies in Urban Schools.

Cohen, D.K., \& Ball, D.L. (1999). Instruction, capacity, and improvement (CPRE Research Report Series RR-043). Philadelphia, PA: University of Pennsylvania Consortium for Policy Research in Education.

Collopy, R. (2003). Curriculum materials as a professional development tool: How a mathematics textbook affected two teachers' learning. The Elementary School Journal, 103(3), 227-311.

Confrey J. \& Stohl V. (Eds.), (2004). On evaluating curricular efficiency: Judging the quality of K-12 mathematics evaluations. Washington D.C.: National Academy Press.

Davis, E.A., \& Krajcik, J. (2005). Designing educative curriculum materials to promote teacher learning. Educational Researcher, 34(3), 3-14.

Education Development Center, Inc. (EDC). (1998). Insights in biology (The matter of life and What on earth? modules). Dubuque, IA: Kendall/Hunt Publishing Company.

Erickson, F. (1986). Qualitative methods in research on teaching. In: M.C. Wittrock (Ed.), Handbook of research on teaching. New York: Macmillan.

Gay, G. (2000). Culturally responsive teaching: Theory, research, and practice. New York, NY: Teachers College Press.

Gess-Newsome, J., Powell, J.C., Taylor, J., \& Gardner, A. (2008) Impacting teacher knowledge, teacher practice, and student achievement: The role of educative curriculum materials and professional development. Paper Presented at the Annual Meeting of the National Association for Research in Science Teaching, Baltimore, MD.

Grossman, P.L. (1990). The making of a teacher: Teacher knowledge and teacher education. New York/ London: Teachers College Press.

Grossman, P., \& Thompson, C. (2004). Curriculum materials: Scaffolds for teacher learning? (No. R-041). Seattle: Center for the Study of Teaching and Policy.

Hewson, P. (2007). Teacher professional development in science. In: S. Abell \& N. Lederman (Eds.), Handbook of research on science education (pp. 1179-1203). Mahwah, NJ: Lawrence Erlbaum Associates.

Hubisz, J. (2003). Middle-school texts don't make the grade. Physics Today, 56 (5): Available at http:// www.physicstoday.org/vol-56/iss-5/p50.html.

Kaskel, A., Hummer, P.J., \& Daniel, L. (2003). Biology: An everyday experience. New York: Glencoe/ McGraw-Hill.

Kesidou, S., \& Roseman, J.E. (2002). How well do middle school science programs measure up? Findings from Project 2061's curriculum review. Journal of Research in Science Teaching, 39(6), 522-549.

Krajcik, J., Blumenfeld, P., Marx, R., \& Soloway, E. (2000). Instructional, curricular, and technological supports for inquiry in science classrooms. In: J. Minstrell \& E. Van Zee (Eds.), Inquiring into inquiry learning and teaching in science (pp. 283-315). Washington, DC: American Association for the Advancement of Science.

Krajcik, J., Mamlok, R., \& Hug, B. (2001). Modern content and the enterprise of science: Science education in the twentieth century. In: L. Corno (Ed.), Education across a century: The centennial volume (pp. 205-231). Chicago: NSSE.

Lazarowitz, R. (2007). High school biology curriculum materials development: Implementation, teaching, and evaluation from the twentieth to the twenty-first century. In: S.K. Abell \& N.G. Lederman (Eds.), Handbook of research on science education (pp. 561-598). Mahwah, NJ: Lawrence Erlbaum Associates.

Leonard, W.H., \& Penick, J.E. (2003). Biology: A community context. New York: Glencoe/McGrawHill.

Loucks-Horsley, S., Hewson, P., Love, N., \& Stiles, K. (1998). Designing professional development for teachers of science and mathematics. Thousand Oaks, CA: Corwin Press.

Magnusson, S., Krajcik, J., \& Borko, H. (1999). Nature, sources, and development of pedagogical content knowledge for science teaching. In: J. Gess-Newsome \& N. Lederman (Eds.), Examining pedagogical content knowledge: The construct and its implications for science education (pp. 95-132). The Netherlands: Kluwer Academic Publishers. 
Marx, R.W., Blumenfeld, P.C., Krajcik, J.S., \& Soloway, E. (1997). Enacting project-based science. The Elementary School Journal, 97(4), 341-358.

McDiarmid, G., Ball, D., \& Anderson, C. (1989). Why staying one chapter ahead doesn't really work: Subject-specific pedagogy. In: M.C. Reynold (Ed.), Knowledge base for the beginning teacher. New York: Pergamon.

McNeill, K.L., \& Krajcik, J. (2008). Scientific explanations: Characterizing and evaluating the effects of teachers' instructional practices on student learning. Journal of Research in Science Teaching, 45(1), 5378.

Miller, K.R., \& Levine, J. (2006). Biology. Upper Saddle River, NJ: Prentice Hall.

National Research Council. (1996). National Science Education Standards. Washington, D.C.: National Academy Press.

National Research Council. (2000). Inquiry and the National Science Education Standards. Washington, DC: National Academy Press.

Petish, D. (2004) Using educative curriculum materials to support new elementary teachers' practice and learning. Unpublished doctoral dissertation. University of Michigan, Ann Arbor.

Pintó, R. (2004). Introducing curriculum innovations in science: Identifying teachers' transformations and the design of related teacher education. Science Education, 89, 1-12.

Powell, J.C., \& Gess-Newsome, J. (2008). The impact of professional development and educative curriculum materials on teacher knowledge, teacher practice, and student achievement: An interim report. Paper Presented at the Annual Meeting of the Association for Science Teacher Education, St. Louis, MO.

Putnam, R., \& Borko, H. (2000). What do new views of knowledge and thinking have to say about research on teacher learning? Educational Researcher, 29(1), 4-15.

Remillard, J.T. (2000). Can curriculum materials support teachers' learning? Two fourth-grade teachers' use of a new mathematics text. The Elementary School Journal, 100(4), 331-350.

Remillard, J.T. (2005). Examining key concepts in research on teachers' use of mathematics curricula. Review of Educational Research, 75(2), 211-246.

Roehrig, G.H., \& Luft, J.A. (2004). Constraints experienced by beginning secondary science teachers in implementing scientific inquiry lessons. International Journal of Science Education, 26(1), 3-24.

Schneider, R. (2006). Supporting science teacher thinking through curriculum materials. In: S.A. Barab, K.E. Hay \& D.T. Hickey (Eds.), Proceeding of the Seventh International Conference of the Learning Sciences (pp. 674-680). Mahwah, NJ: Lawrence Erlbaum Associates.

Schneider, R., \& Krajcik, J. (2002). Supporting science teacher learning: The role of educative curriculum materials. Journal of Science Teacher Education, 13(3), 221-245.

Schneider, R., Krajcik, J., \& Blumenfeld, P. (2005). Enacting reform-based science materials: The range of teacher enactments in reform classrooms. Journal of Research in Science Teaching, 42(3), 283312 .

Shulman, L.S. (1986). Those who understand: Knowledge growth in teaching. Educational Researcher, 15(5), 4-14.

Stake, R.E., \& Easley, J.A. (1978). Case studies in science education, Vol. 2. Washington, D.C.: U.S. Government Printing Office. (No. 038-000-00376-3).

Stern, L., \& Roseman, J.E. (2004). Can middle-school science textbooks help students learn important ideas? Findings from project 2061's curriculum evaluation study: Life science. Journal of Research in Science Teaching, 41(6), 538-568.

Sullivan, J.P. (2008). The use of photographs to portray urban ecosystems in six introductory environmental science textbooks. Journal of Research in Science Teaching 45(9), 1003-1020.

Tarr, J.E., Chavez, O., Reys, R.E., \& Reys, B.G. (2006). From the written to the enacted curricula: The intermediary role of middle school mathematics teachers in shaping students' opportunity to learn. School Science and Mathematics, 106(4), 191-201.

Weiss, I.R., Banilower, E.R., McMahon, K.C., \& Smith, P.S. (2001). Report of the 2000 National Survey of Science and Mathematics Education. Chapel-Hill, NC: Horizon Research, Inc. Retrieved Jan. 12, 2007, from http://2000survey.horizon-research.com/reports/status/complete.pdf. 
Welch, W.W. (1979). Twenty years of science curriculum development: A look back. Review of Research in Education, 7, 282-308.

Windschitl, M. (2002). Inquiry projects in science teacher education: What can investigative experiences reveal about teacher thinking and eventual classroom practice? Science Education, 87(1), 112143.

Zembal-Saul, C., \& Dana, T.M. (2000). Exploring the nature, sources, and development of pedagogical content knowledge for supporting children's scientific inquiry (PCK-SI). A Paper Presented at the Annual Meeting of the National Association for Research in Science Teaching, New Orleans, LA. 